\title{
Fabrication of contact lens containing high-performance wire grid polarizer
}

\author{
Young Jae Shin, ${ }^{\text {a }}$ Min Jae Shin, ${ }^{b \dagger}$ L Jay Guo ${ }^{c^{*}}$ and Jae Sup Shin ${ }^{\mathrm{d}^{*}}$
}

\begin{abstract}
Contact lenses containing high-performance wire grid polarizers (WGPs) were fabricated. The base polymeric membrane was synthesized by copolymerization of 2-hydroxyethyl methacrylate, 3-[tris(trimethylsiloxy)silyl]propyl methacrylate, 1-vinyl-2-pyrrolidinone, methyl methacrylate and ethylene glycol dimethacrylate. The nanopattern was formed by nanoimprint lithography using a UV-curable rubber-toughened epoxy resin on the base membrane. Two consecutive angled aluminium evaporations were performed on the nanopattern, followed by reactive ion etching to form the WGP. The WGP on the membrane was then covered by another layer of the base polymeric material to form the final contact lens. This membrane demonstrated high performance as a polarizer, confirmed by measuring transmittance of transverse magnetic polarized light and transverse electric polarized light. This membrane also demonstrated good performance as a contact lens in terms of modulus, water content and oxygen permeability.
\end{abstract}

(c) 2017 Society of Chemical Industry

Keywords: wire grid polarizer; contact lens; nanoimprint lithography; angled evaporation

\section{INTRODUCTION}

Polarizers are essential components of many electronic devices and are used in a variety of applications such as in liquid-crystal displays and three-dimensional viewing glasses. Conventional polarizers are manufactured using iodine-doped poly(vinyl alcohol) film. However, there is serious loss of light transmittance in these materials due to absorption of light by this type of polarizer film. It is also difficult to use most common polarizers in very small electronic devices. Therefore, wire grid polarizers (WGPs) have received a large amount of research attention as a next-generation category of polarizers. ${ }^{1-13}$ WGPs are formed by arranging nanometer-scale metal wires on transparent substrates. Transverse magnetic (TM) polarized light is transmitted through WGPs, while transverse electric (TE) polarized light is reflected. Because WGPs can be formed on very small size scales, it is possible to integrate them into new microelectronic devices. Due to the design push towards microelectronic devices, WGPs could be effective components in new devices in fields such as microscopy, beam splitters and other imaging systems, as well as leading to brighter liquid-crystal display screens due to recycling of light. However, these practical applications require further investigation of WGP fabrication before becoming a reality..$^{1-13}$

In order to fabricate a WGP, a metal grating must be well arranged on a substrate. Nanoimprint methods are among the easiest for forming the grating structure. Nanoimprint lithography has received a great deal of attention as a next-generation lithographic technique that could replace current lithographic methods used in the electronics industry. Using nanoimprint lithography, several hundred nanopattern copies can be formed using the same template. Compared with traditional photolithography, nanoimprint lithography is far superior in terms of production speed and economic feasibility. Development of these new lithographic techniques is an ongoing process in the electronics industry. ${ }^{14-19}$
WGPs have been manufactured using nanoimprinting, as reported previously. ${ }^{20-28}$ In order to demonstrate their high performance as polarizers in the visible light spectrum, the period of the WGP array must be less than $100 \mathrm{~nm}$. Even though WGPs with periods of the order of $10^{1} \mathrm{~nm}$ have already been reported, it is still very difficult to reliably form nanopatterns with $100 \mathrm{~nm}$ periods without defects. To that end, we have found a novel method to make WGPs with $110 \mathrm{~nm}$ periods by using a $220 \mathrm{~nm}$ period nanopattern in consecutive angled aluminium evaporation steps and reactive ion etching. ${ }^{29}$ Because this WGP has a viewing angle problem, we have also reported a $90 \mathrm{~nm}$ period WGP fabricated in a similar manner with a $180 \mathrm{~nm}$ period nanopattern. ${ }^{30}$

Contact lenses are traditionally made using poly(dimethyl methacrylate) as a base material, but they can be improved greatly by using poly(2-hydroxyethyl methacrylate) (PHEMA). ${ }^{31-33}$ While PHEMA has many favorable physical properties for use in contact lenses, it has a low oxygen permeability which is not suitable due to the need for oxygen flow from air to the cornea. Because

\footnotetext{
* Correspondence to: LJ Guo, Macromolecular Sciences and Engineering, University of Michigan, Ann Arbor, USA. E-mail: guo@umich.edu; or JS Shin, Department of Chemistry, Chungbuk National University, Cheongju, Korea. E-mail: jsshin@chungbuk.ac.kr

$\dagger$ These authors contributed equally to this work

a Department of Physics, Harvard University, Cambridge, USA

b School of Integrated Oriental Medical Bioscience, Semyung University, Jecheon, Korea

c Macromolecular Sciences and Engineering, Department of Electrical Engineering and Computer Science, and Department of Mechanical Engineering, University of Michigan, Ann Arbor, USA
}

d Department of Chemistry, Chungbuk National University, Cheongju, Korea 
blood vessels are not connected to the human cornea, oxygen must be supplied from the atmosphere. Therefore, the oxygen permeability of contact lenses must be above 24 DK during the day. In addition, in order to use a contact lens while sleeping, the oxygen permeability of the contact lens must be above 87 DK. ${ }^{33}$ A great deal of research has been conducted in the last 20 years to increase the oxygen permeability of contact lenses. Many hydrophilic monomers have been copolymerized with PHEMA to fabricate contact lenses. Recently, a silicone-containing hydrogel moiety has been shown to increase oxygen permeability. ${ }^{34-38}$

In our previous study, embedding a WGP into a flexible material was attempted for the first time. ${ }^{39}$ Polydimethylsiloxane was used as a flexible material. Because polydimethylsiloxane has good biocompatibility and oxygen permeability, it could be said that the analogous contact lens containing WGP was fabricated. Because the WGP used in the study had a $180 \mathrm{~nm}$ period, a serious problem in the viewing angle occurred. ${ }^{30}$

In the study reported here, we fabricated a WGP which had a $90 \mathrm{~nm}$ period nanopattern and did not have the viewing angle problem. And a contact lens containing the WGP was fabricated using materials which were used to manufacture real contact lenses. For the first time a real contact lens containing a high-performance WGP was introduced in our study.

\section{EXPERIMENTAL}

\section{Materials}

2-Hydroxyethyl methacrylate (HEMA), 1-vinyl-2-pyrrolidinone (NVP), methyl methacrylate (MMA), ethylene glycol dimethacrylate (EGDMA), 3-[tris(trimethylsiloxy)silyl]propyl methacrylate (TSPMA), 2-hydroxy-2-methylpropiophenone (HMPP), triarylsulfonium hexafluoroantimonate salt (TSHA; $50 \mathrm{wt} \%$ in propylene carbonate) and propylene glycol monomethyl ether acetate (PGMEA) were purchased from Aldrich Chemical (St Louis, MO, USA). HMPP was used as a photoinitiator for the polymerization of the base membrane materials. TSHA was used as a photoacid generator for the nanoimprinting process. Bisphenol F-type epoxy resin (YDF-170) and NBR-based epoxy resin (R-1309) were purchased from Kukdo Chemical (Korea). The adhesion promoter Silquest A-187 silane ((3-glycidyloxypropyl)trimethoxysilane as the main ingredient) was purchased from Crompton Co. (Lisle, IL, USA). The mold release agent $1 H, 1 H, 2 H, 2 H$-perfluorodecyltrichlorosilane (FDTS) was purchased from Gelest Inc. (Morrisville, PA, USA).

\section{Instrumentation}

The nanoimprinting was conducted using a Nanonex NX2000 imprinting tool (Monmouth Junction, NJ, USA) with vacuum capability and an ELC-430 UV curing system (Electro-Lite Corporation, Bethel, CT, USA). The deposition of aluminium was conducted using electron-beam evaporation. Reactive ion etching was conducted using an LAM 9400 tool (LAM Research Corporation, Fremont, CA, USA). Transmission of TM and TE was measured using equipment that we made ourselves with a Nikon Eclipse TE300 microscope (Tokyo, Japan), HR4000CG spectrometer (Ocean Optics Inc., Dunedin, FL, USA), and TE and TM were measured more than five times and the value was obtained by averaging the results. The viewing angle was measured by tilting the sample. SEM was conducted using a Hitachi SU8000 scanning electron microscope (Tokyo, Japan). An Instron5944 universal testing machine (Norwood, MA, USA) was used to estimate the tensile strength, elongation and modulus. The length, width and thickness of a specimen were $60 \mathrm{~mm}, 10 \mathrm{~mm}$ and $100 \mu \mathrm{m}$, respectively.

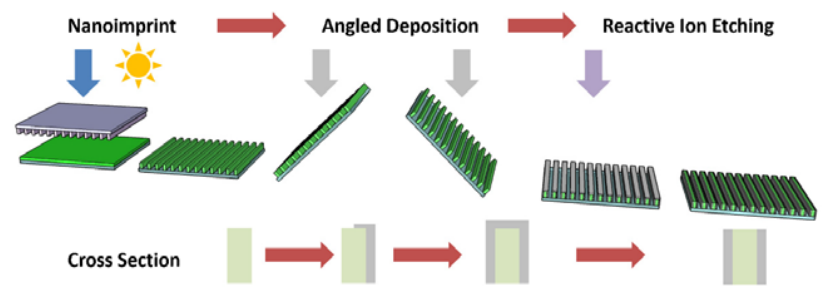

Figure 1. Schematic of double-angled aluminium evaporation and reactive ion etching in the WGP formation process.

\begin{tabular}{|c|c|c|c|c|}
\hline Component & $\begin{array}{c}\text { Amount } \\
\text { (mmol) }\end{array}$ & $\begin{array}{c}\text { Amount } \\
\text { (mol\%) }\end{array}$ & $\begin{array}{c}\text { Weight } \\
\text { (g) }\end{array}$ & $\begin{array}{c}\text { Weight } \\
\text { (\%) }\end{array}$ \\
\hline HEMA & 131 & 89.8 & 17.0 & 85.0 \\
\hline NVP & 8.10 & 5.55 & 0.900 & 4.50 \\
\hline MMA & 2.00 & 1.37 & 0.200 & 1.00 \\
\hline TSPMA & 4.26 & 2.92 & 1.80 & 9.00 \\
\hline EGDMA & 0.504 & 0.346 & 0.100 & 0.500 \\
\hline HMPP & 0.609 & & 0.100 & \\
\hline
\end{tabular}

A minimum of six specimens were tested, and the average results were reported. An Atago Nar $1 \mathrm{~T}$ Abbe refractometer was used to measure the reflective index at $22^{\circ} \mathrm{C}$. LED (wavelength of D-line) was used as a light source in the refractometer. The oxygen permeability was measured using a $201 \mathrm{~T}$ permeometer (Jurong East, Singapore) at $35 \pm 0.5^{\circ} \mathrm{C}$. Before measuring the oxygen permeability, the membrane was soaked in a solution of $0.142 \mathrm{~mol} \mathrm{~L}^{-1} \mathrm{NaCl}$ for at least $24 \mathrm{~h}$. A gravimetric method was used to measure the water content, which was estimated by measuring the weight of the swollen state in water $\left(W_{s}\right)$ and the weight of dried state $\left(W_{d}\right)$ :

$$
\text { Water content }(\%)=\frac{W_{s}-W_{d}}{W_{s}} \times 100
$$

\section{Polymerization of component materials for contact lens}

HEMA, NVP, MMA, TSPMA and EGDMA were copolymerized with HMPP as a photoinitiator in a Teflon mold. The stock solution was prepared by mixing HEMA $(17.00 \mathrm{~g}, 0.131 \mathrm{~mol}), \mathrm{MMA}$ $(0.200 \mathrm{~g}, 2.00 \mathrm{mmol}), \operatorname{NVP}(0.900 \mathrm{~g}, 8.10 \mathrm{mmol})$, EGDMA $(0.100 \mathrm{~g}$, $0.504 \mathrm{mmol})$ and TSPMS $(1.80 \mathrm{~g}, 4.26 \mathrm{mmol})$. HMPP $(0.100 \mathrm{~g}$, $0.609 \mathrm{mmol}$ ) was then added to the stock solution. The polymerization was conducted under UV light for $20 \mathrm{~min}$ at room temperature. The synthesized polymer was cast as a film, which was used for estimating the mechanical properties. In order to form the base membrane for the contact lens, the amount of resin was adjusted to obtain a final thickness of $50 \mu \mathrm{m}$.

\section{Nanoimprint process}

In order to achieve easy release from the original silicon oxide master mold after finishing the imprinting process, the mold was vapor-coated with FDTS. And Silquest A-187 silane was used as an adhesion promoter to increase the adhesive strength between the base membrane and the nanopattern. The nanoimprint resist formulation was made by dissolving bisphenol F-type resin and NBR-based epoxy resin in PGMEA with a mixing ratio of 85:15 (YDF-170:R-1309), ${ }^{40}$ and was followed by the addition of TSHA (3.0 wt\% to the epoxy resin). Using spin coating, a very thin film 
(a)

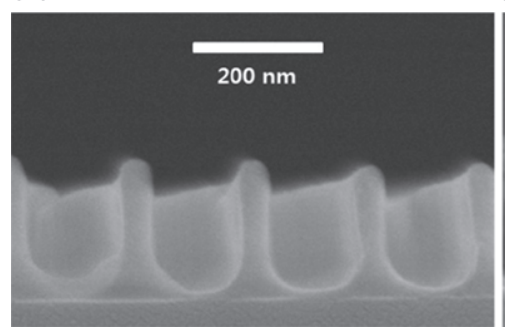

(b)

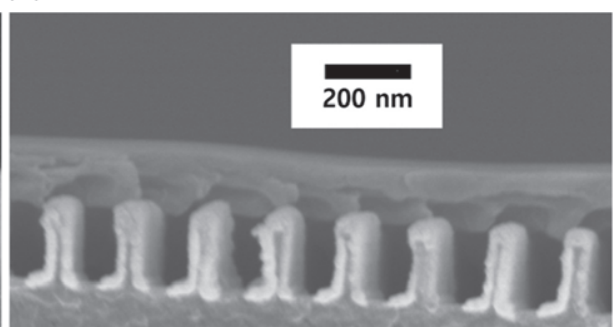

(c)

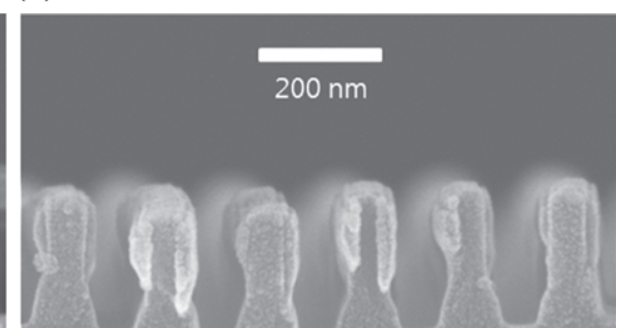

Figure 2. SEM images of nanopatterns (a) after nanoimprinting, (b) after angled aluminium evaporation and (c) after reactive ion etching.

(a)

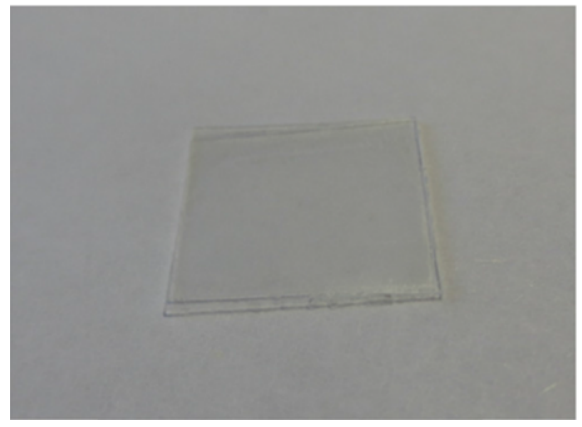

(b)

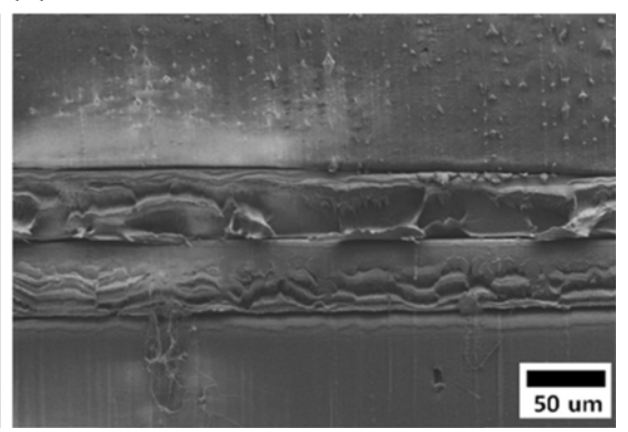

Figure 3. (a) Photo of the lens containing the WGP and (b) SEM image of the cross-section of the lens.

was formed on the base membrane. The thickness of the film was controlled by changing the concentration of the resin. By using larger amounts of PGMEA, a thinner nanoimprint could be obtained. The imprinting pressure was typically less than $50 \mathrm{psi}$ (345 $\mathrm{kPa}$ ) due to the low viscosity of the epoxy resin. A reaction time of $10 \mathrm{~min}$ was sufficient to cure the epoxy resin.

\section{Aluminium deposition}

The deposition mount was tilted to $40^{\circ}$ to deposit aluminium on the sidewalls of the imprinted nanopattern, but it was not deposited on the base of the trench. The rate of aluminium deposition was $0.5 \mathrm{~nm} \mathrm{~s}^{-1}$. In order to deposit aluminium on both sidewalls of the nanopatterns, the aluminium deposition process was repeated from the opposite direction. ${ }^{31,32}$ The final aluminium thickness on both sidewalls was controlled to be $20 \mathrm{~nm}$. This process is shown in Fig. 1.

\section{Reactive ion etching process}

The aluminium layer deposited on top of the nanopattern needed to be removed in order to form the grid pattern. We used an anisotropic plasma etching process to selectively remove the top aluminium layer while leaving the aluminium on the sidewalls of the grating relatively intact. Aluminium etching was performed using a LAM 9400 tool (Fremont, CA, USA). The detailed process has been previously reported. ${ }^{29,30}$ The overall fabrication process of the WGP is illustrated in Fig. 1.

\section{RESULTS AND DISCUSSION}

\section{Fabrication of contact lens containing WGP}

In this study, we fabricated contact lenses containing high-performance WGPs for practical use, aiming to achieve not only high polarization performance but also high performance as a contact lens. Therefore, we used materials that demonstrate both excellent mechanical properties and favorable oxygen permeability. First, we selected the materials for fabricating the contact lens, and then made the membrane via polymerization. Many different formulations have been used to make contact lenses. According to our previous research results, we selected a lens formulation which demonstrates excellent physical properties. Therefore we conducted the copolymerization of HEMA, NVP, MMA, TSPMA and EGDMA to form the contact lens, and used HMPP as a photoinitiator. The formulation used in this study is detailed in Table 1.

HEMA has been one of the most widely used materials for making contact lenses since they were first introduced in 1962. PHEMA has good physical properties for use in contact lenses; because the pendent hydroxyl groups in PHEMA can interact with water, contact lenses made with this material position themselves properly on the eye. MMA is used to reinforce the desired mechanical properties, and EGDMA serves a similar purpose through crosslinking reactions. MMA and EGDMA can aid the manufacturing process in maintaining the shape of the lens. NVP is a hydrophilic monomer that can increase the water content of the contact lens. TSPMA is used to increase the oxygen permeability because it has a large number of silicon groups at the side chains. HMPP was used as a photoinitiator at $0.5 \mathrm{wt} \%$.

All of these components were mixed thoroughly, and the photopolymerization was carried out using UV irradiation on the Teflon mold $(1.50 \mathrm{~cm} \times 1.50 \mathrm{~cm})$. The thickness of the membrane was controlled to $50 \pm 2 \mu \mathrm{m}$ after polymerization was completed. Nanoimprinting was then carried out on this membrane using an epoxy resin at a mixing ratio of 85:15 (YDF-170:R-1309), which was selected due to its high adhesive strength. The original silicon oxide mold $(1.10 \mathrm{~cm} \times 1.10 \mathrm{~cm})$ used for nanoimprinting featured a nanopattern with a $180 \mathrm{~nm}$ period, a $110 \mathrm{~nm}$ linewidth and a $200 \mathrm{~nm}$ height. Before the nanoimprinting, Silquest A-187 silane was vapor-coated on the membrane to increase the adhesive strength between the membrane and the nanopattern. In the 


\begin{tabular}{|c|c|c|c|c|c|c|}
\hline $\begin{array}{l}\text { Relative } \\
\text { humidity (\%) }\end{array}$ & $\begin{array}{c}\text { Tensile } \\
\text { strength (MPa) }\end{array}$ & Elongation (\%) & $\begin{array}{l}\text { Modulus } \\
\text { (MPa) }\end{array}$ & $\begin{array}{l}\text { Refractive } \\
\text { index }\end{array}$ & $\begin{array}{c}\text { Water } \\
\text { content (\%) }\end{array}$ & $\begin{array}{c}\text { Oxygen } \\
\text { permeability (DK) }\end{array}$ \\
\hline 16 & $1.82 \pm 0.09$ & $54.7 \pm 3.1$ & $3.33 \pm 0.18$ & & & \\
\hline 98 & $0.27 \pm 0.02$ & $172.5 \pm 8.5$ & $0.16 \pm 0.01$ & $1.435 \pm 0.0005$ & $37.8 \pm 1.7$ & $27.4 \pm 1.3$ \\
\hline
\end{tabular}
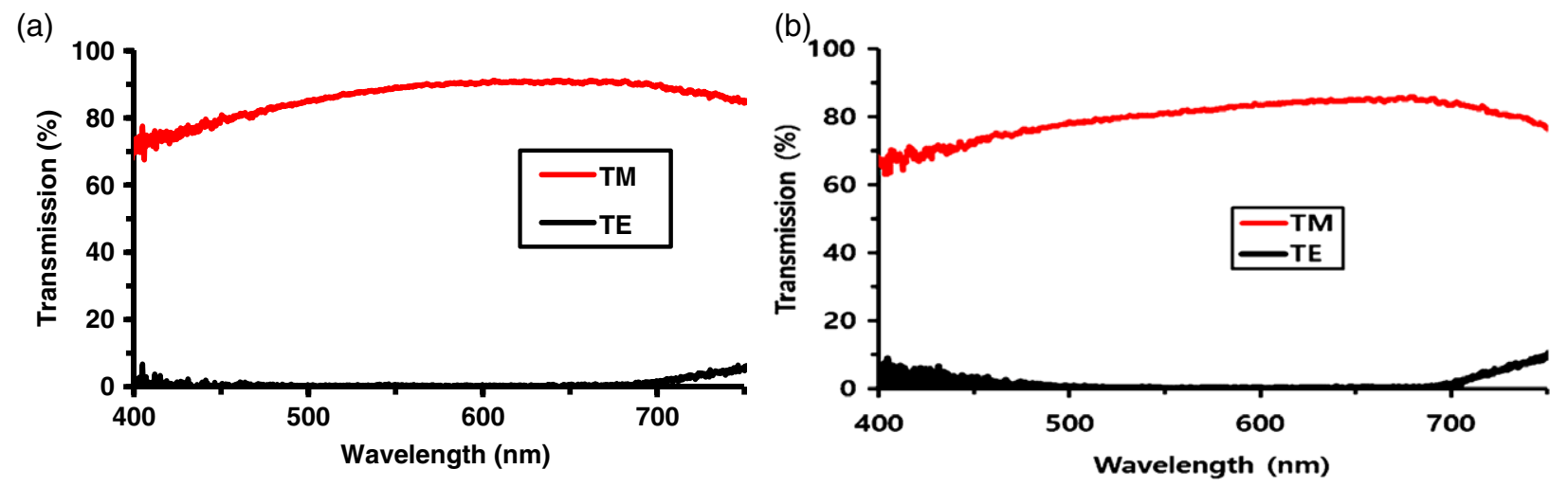

Figure 4. TE and TM curves of contact lenses with nanoimprinted WGP, under RH of (a) $16 \%$ and (b) $98 \%$.

early stages of this study, we used both surface modification of the base membrane by oxygen plasma and Silquest A-187 treatment to increase the adhesive strength. However, because the results showed that Silquest $A-187$ treatment alone was enough to achieve the desired adhesive strength, only Silquest A-187 treatment was carried out to increase the adhesive strength between the base membrane and the nanopatterns. Surface treatment with FDTS was done on the silicon oxide mold in order to better control the demolding process.

An SEM image of the nanopattern formed after nanoimprinting is shown in Fig. 2(a). The nanopattern was formed with a $180 \mathrm{~nm}$ period, $70 \mathrm{~nm}$ linewidth and $200 \mathrm{~nm}$ height. After the nanopattern was tilted $40^{\circ}$, aluminium was then deposited by evaporation. This process was done again from the exact opposite direction. The thickness of the deposited aluminium on the sidewall was controlled to be $20 \mathrm{~nm}$, as our previous studies show that a WGP has the best performance as a polarizer in the case of an aluminium thickness of $20 \mathrm{~nm} .{ }^{29}$ An SEM image is shown in Fig. 2(b) after aluminium deposition. The upper side of the aluminium was removed by reactive ion etching, leaving aluminium only at the side walls. Finally, the WGP was fabricated with a $90 \mathrm{~nm}$ period and $20 \mathrm{~nm}$ linewidth. An SEM image of the WGP is shown in Fig. 2(c). A schematic of the WGP fabrication is shown in Fig. 1. The same formulation used to make the base membrane was used for covering the formed WGP. The thickness of the membrane covering the WGP was controlled to $50 \pm 2 \mu \mathrm{m}$, and the final WGP-containing membrane had a total thickness of $100 \pm 4 \mu \mathrm{m}$. A photo of the final lens is shown in Fig. 3(a) and an SEM image of the cross-section is shown in Fig. 3(b). In Fig. 3(b), the bottom layer is the base membrane and the upper layer is the covering membrane. The WGP is located between the two layers.

\section{Physical properties of lens containing WGP}

The physical properties of the fabricated membrane relevant to its use as a contact lens (such as tensile strength, elongation, modulus, refractive index, water content and oxygen permeability) were measured. The fabricated membrane behaved like a hydrogel, meaning that the physical properties are influenced by humidity; as a result, measurements were recorded at two different relative humidity $(\mathrm{RH})$ levels of 16 and $98 \%$. When the contact lens is inserted in eye, it will be wet through with tears. Considering this condition the physical properties of the sample were estimated at $98 \% \mathrm{RH}$. And in order to compare the data for general condition, they were also estimated at $16 \% \mathrm{RH}$. Prior to measurement, the specimens were held at these conditions for $6 \mathrm{~h}$ in order to reach equilibrium.

The results are presented in Table 2. The results show that this material has suitable physical properties for use as a contact lens. In particular, the oxygen permeability of the membrane is $27.4 \mathrm{DK}$, which is superior to that of the general PHEMA-based material. This feature can help to decrease oxygen-related malfunctions of the lens.

The results show that the film formed in this study has enough tensile strength compared with a commercial soft contact lens, and its elongation and modulus were in the range of that of a

\begin{tabular}{|c|c|c|c|c|}
\hline $\begin{array}{l}\text { Relative } \\
\text { humidity (\%) }\end{array}$ & $450 \mathrm{~nm}$ & $550 \mathrm{~nm}$ & $650 \mathrm{~nm}$ & $750 \mathrm{~nm}$ \\
\hline 16 & $80.9 / 0.01$ (8090) & $89.2 / 0.10$ (892) & $91.1 / 0.10(911)$ & $85.1 / 4.78(17.8)$ \\
\hline 98 & 72.9/1.89 (38.6) & $81.2 / 0.13(625)$ & $85.1 / 0.22$ (387) & $77.0 / 9.26(8.32)$ \\
\hline
\end{tabular}


(a)

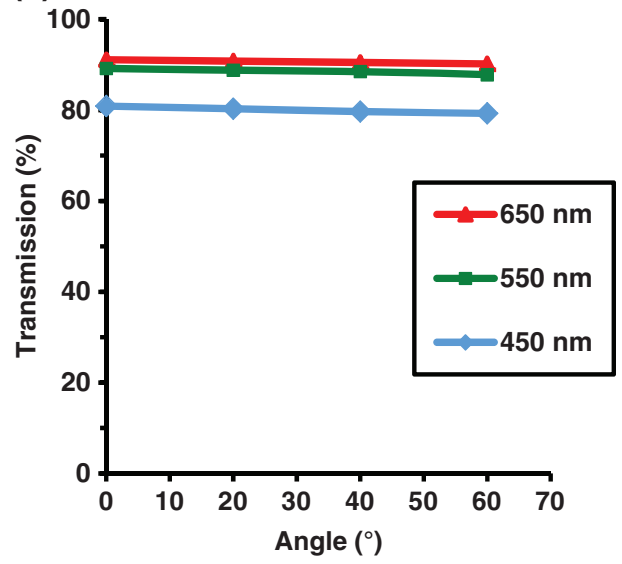

(b)

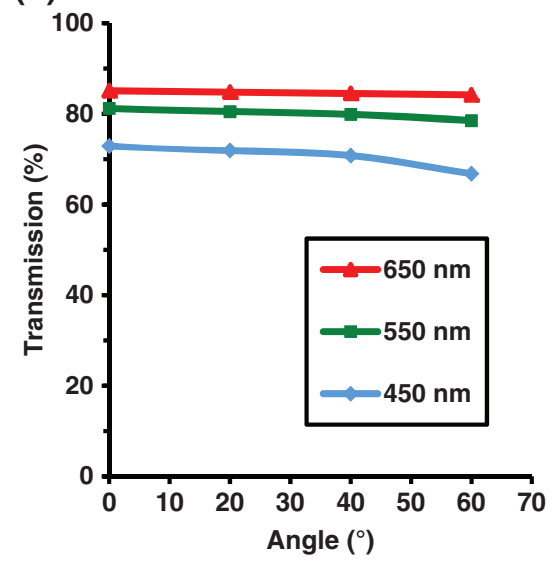

Figure 5. Transmission of TM light through the nanoimprinted WGP lens at different angles, at (a) $16 \% \mathrm{RH}$ and (b) $98 \% \mathrm{RH}$.

\begin{tabular}{|c|c|c|c|c|c|c|c|c|c|}
\hline \multirow{2}{*}{$\begin{array}{l}\text { Relative } \\
\text { humidity } \\
\text { (\%) }\end{array}$} & \multicolumn{3}{|c|}{$450 \mathrm{~nm}$} & \multicolumn{3}{|c|}{$550 \mathrm{~nm}$} & \multicolumn{3}{|c|}{$650 \mathrm{~nm}$} \\
\hline & $20^{\circ}$ & $40^{\circ}$ & $60^{\circ}$ & $20^{\circ}$ & $40^{\circ}$ & $60^{\circ}$ & $20^{\circ}$ & $40^{\circ}$ & $60^{\circ}$ \\
\hline 16 & $80.3 / 0.02(4015)$ & 79.7/0.01 (7970) & 79.3/0.01 (7930) & $88.8 / 0.11(807)$ & $88.5 / 0.08(1106)$ & $87.8 / 0.09$ (975) & $90.8 / 0.11(825)$ & $90.5 / 0.09(1006)$ & $90.2 / 0.10(902)$ \\
\hline 98 & $71.9 / 1.42(50.6)$ & $70.8 / 0.11(644)$ & $66.8 / 0.17(405)$ & $80.5 / 0.12(671)$ & 79.9/0.11 (726) & $78.5 / 0.18(436)$ & $84.8 / 0.21(404)$ & $84.5 / 0.22(384)$ & $84.2 / 0.20(421)$ \\
\hline
\end{tabular}

general soft contact lens. ${ }^{41-43}$ The water content increased proportionally with the amount of NVP in the formulation, and the oxygen permeability also increased proportionally with it. ${ }^{44}$ Therefore, if the NVP amount in the formulation is increased, water content and oxygen permeability may be increased. But because such an increase reduces the tensile strength and modulus, it leads to problems in the lens manufacture and the nanoimprinting process in this study. Therefore we think that the present formulation is the optimum one.

TE and TM values of the membrane were measured in order to estimate its potential as a polarizer, and the results are shown in Fig. 4. For the results shown, the TM values in the visible wavelength region were around $80 \%$ transmittance at both 16 and $98 \% \mathrm{RH}$, while the TE values were almost $0 \%$ in both cases. This result shows that this membrane can act as an effective polarizer.

The TM/TE ratio is defined as the extinction ratio, and its value as a function of excitation wavelength is presented in Table 3. In the case of $16 \% \mathrm{RH}$, the highest extinction ratio occurred at $450 \mathrm{~nm}$. Because the extinction ratio largely depends on the TE value, even though the maximum TM value occurred at $650 \mathrm{~nm}$, the highest extinction ratio was at $450 \mathrm{~nm}$ where the lowest TE value occurred. In the case of $98 \% \mathrm{RH}$, the highest extinction ratio was at $550 \mathrm{~nm}$. A humidity increase leads to a decrease in the TM value and increases the TE value. We think that these results are due to the light scattering by water.

Another important property of a polarizer is the viewing angle. The transmission of TM light through the polarizer was measured at different viewing angles at wavelengths of 650,550 and $450 \mathrm{~nm}$. The results are shown in Fig. 5. And the measured optical transmissions of TM/TE polarized light through the WGP at different angle are summarized in Table 4. In Fig. 5 and Table 4, at $16 \% \mathrm{RH}$, no decrease in transmission was observed at less than a $60^{\circ}$ viewing angle. At $98 \% \mathrm{RH}$, a minor decrease in transmission occurred at $450 \mathrm{~nm}$. Therefore, we can conclude that this WGP has a wide viewing angle.

Water content and oxygen permeability of the contact lens sample containing the WGP were estimated and the values were compared with those in Table 2 . The estimated water content was $36.3 \pm 1.9 \%$. This means a reduction of only $4 \%$. We concluded that embedding of the WGP did not have much effect to the water content. But the estimated oxygen permeability of the contact lens sample containing the WGP was reduced from $27.4 \pm 1.3$ to $21.5 \pm 1.5 \mathrm{DK}$. This result showed that embedding of the WGP had an effect on the oxygen permeability. And we suggest that 21.5 DK is not so bad a value for a contact lens, but it needs to be improved.

\section{CONCLUSIONS}

Contact lenses containing WGPs were fabricated in this study. Copolymerization of HEMA, MMA, NVP, TSPMA and EGDMA was used to synthesize the base membrane for the lens. In making the WGP, a $180 \mathrm{~nm}$ period nanopattern was formed using rubber-toughened epoxy and nanoimprinting on the base membrane, and the WGP was formed by two angled aluminium evaporation steps followed by reactive ion etching. This WGP had a $90 \mathrm{~nm}$ period and a $20 \mathrm{~nm}$ linewidth. The same polymeric compound used to make the base membrane was then used to cover the WGP. The formed membrane has very good physical properties for use as a contact lens, as well as favorable optical properties for use as a polarizer.

\section{ACKNOWLEDGEMENTS}

This paper was supported by the Semyung University Research Grant of 2016. 


\section{REFERENCES}

1 Meng F, Luo G, Maximov I, Montelius L, Chu J and Xu H, Microelectron Eng 88:3108 (2011)

2 Ahn SH, Kim JS and Guo LJ, J Vac Sci Technol B 25:2388 (2007).

3 Lee JH, Song Y-W, Hwang KH, Lee J-G, Ha J and Zang D-S, Opt Express 16:16867 (2008).

4 Chen CM, An TP, Hung Y-M and Sung C-K, Microelectron Eng 88:2135 (2011).

5 Kim T-I and Seo S-M, Nanotechnology 20:145305 (2009).

6 Kim M-K, Kim M, Lim YJ, Her H, Ge Z, Wu S-T et al., Curr Appl Phys 11:582 (2011).

7 Kim SH, Park J-D and Lee K-D, Nanotechnology 17:4436 (2006).

8 Suzuki M, Takada A, Yamada T, Hayasaka T, Sasaki K, Takahashi E et al., J Nanophoton 5:51501 (2011).

9 Ahn S-W, Lee K-D, Kim J-S, Kim SH, Park J-D, Lee SH et al., Nanotechnology 16:1874 (2005).

10 Wu T, Ge Z and Wu S-T, Appl Phys Lett 92:051109 (2008).

11 Park KS, Dang JM, Sung MM and Seo S-M, Nanoscale Res Lett 7:1 (2012).

12 Ge Z, Xinyu Z and Wu S-T, J Disp Technol 2:102 (2006).

13 Ge Z and Wu S-T, Appl Phys Lett 93:121104 (2008).

14 Chou SY, Krauss PR and Renstrom PJ, Appl Phys Lett 67:3114 (1995).

15 Chou SY, Krauss PR and Renstrom PJ, Science 272: 85 (1996).

16 Guo LJ, Adv Mater 19:495 (2007).

17 Choi P, Fu PF and Guo LJ, Adv Funct Mater 17:65 (2007).

18 Cheng X, Guo LJ and Fu PF, Adv Mater 17:1419 (2005).

19 Ahn SH and Guo LJ, Adv Mater 20:2044 (2008).

20 Golden JH, DiSalvo FJ, Silcox J, Thomas M and Elman J, Science 273:782 (1996).

21 Liu X, Deng X, Sciortino JP, Buonanno M, Walters F, Varghese R et al., Nano Lett 6:2723 (2006).

22 Pang YT, Meng GW, Zhang LD, Qin Y, Gao XY, Zhao AW et al., Adv Funct Mater 12:719 (2002).
23 Wang JJ, Chen L, Liu XM, Sciortino P, Liu F, Walters F et al., Appl Phys Lett 89:141105 (2006).

24 Wang JJ, Walters F, Liu XM, Sciortino P and Deng XG, Appl Phys Lett 90:061104 (2007).

25 Pais A, Banerjee A, Klotzkin D and Papautsky I, Lab Chip 8:794 (2008).

26 Wang JJ, Zhang W, Deng X, Deng J, Liu F, Sciortino P et al., Opt Lett 30:195 (1995).

27 Gardner E and Hansen D, SID Symp Digest Tech Paper 34:62 (2003).

28 Chen L, Wang JJ, Walters F, Deng X, Buonanno M, Tai S et al., J Vac SCi Technol B 25:2654 (2007).

29 Shin YJ, Pina-Hernandez C, Wu YK, Ok JG and Guo LJ, Nanotechnology 23:344018 (2012).

30 Shin YJ, Wu Y-K, Lee KT, Ok JG and Guo LJ, Adv Opt Mater 1:863 (2013).

31 Nicolson PC and Vogt J, Biomaterials 22:3273 (2001).

32 Maldonado-Codina C and Efron N, Optom Practice 4:101 (2003).

33 Holden BA and Mertz GW, Invest Ophthalmol Vis Sci 25:1161 (1984).

34 Phan CM, Subbaraman L, Liu L, Gu F and Jones L, J Biomater Sci Polym Ed 25:18 (2014).

35 Awasthi AK, Meng FR, Kunzler JF, Linhardt JG, Papagelis P, Oltean G et al., Polym Adv Technol 24:557 (2013).

36 Karlgard CCS, Wong NS, Jones LW and Moresoli C, Int J Pharm 257:141 (2003).

37 Kwon Y, Song M, Hwang YG, Chang SH and Hong WJ, Curr Appl Phys 8:486 (2008).

38 Xu J, Yang P, Zhang L and Huo G, J Appl Polym Sci 132:41399 (2015).

39 Hollowell AE and Guo LJ, Adv Opt Mater 1:343 (2013).

40 Shin YJ, Wu Y-K and Guo LJ, Nanotechnology 24:255302 (2013).

41 Bhamra TS and Tighe BJ, Contact Lens Anterior Eye 40:70 (2017).

42 Lin Z, Yu W, Wang J and Jin X, React Funct Polym 67:789 (2007).

43 Lou X and Coppennhagen C, Polym Int 50:319 (2001).

44 Wang Y, Tan G, Zhang S and Guang Y, Appl Surf Sci 255:604 (2008). 